\title{
Ação residual de agrotóxicos pulverizados em plantas de milho sobre Trichogramma pretiosum ${ }^{1}$
}

\author{
Rafael Antonio Pasini²*, Anderson Dionei Grützmacher ${ }^{2}$, Daniel Spagnol ${ }^{2}$, Franciele Silva de Armas ${ }^{3}$, \\ Andréia Vös Normberg ${ }^{4}$, Helbert Júnior da Silva Carvalho ${ }^{5}$
}

10.1590/0034-737X201764030004

\section{RESUMO}

Objetivou-se, com este trabalho, avaliar a ação residual de nove inseticidas e de um fungicida-acaricida sobre o parasitoide Trichogramma pretiosum (Riley, 1879), em condições de semicampo, sob telado. Plantas de milho foram pulverizadas com os agrotóxicos até o ponto de escorrimento, três dias antes da montagem dos ensaios. Ovos de Anagasta kuehniella (Zeller, 1879) foram ofertados, em cartelas de cartolina azul, individualizadas no interior de gaiolas. Os adultos recém-emergidos de T. pretiosum foram liberados na proporção de 1,6 fêmeas por ovo do hospedeiro alternativo. As liberações de T. pretiosum foram realizadas aos 3, 10, 17, 24 e 31 dias após a pulverização das plantas. Os agrotóxicos foram classificados quanto a sua persistência, seguindo-se a escala proposta pela IOBC. Os resultados mostraram que os produtos comerciais-ingredientes ativos $\left(\mathrm{kg} \mathrm{ou} \mathrm{L} \mathrm{ha}^{-1}\right)$ usados na cultura do milho, beta-ciflutrina $(0,10)$, cipermetrina $(0,08)$, clorpirifós $(1,00)$, lambda-cialotrina $50(0,15)$, enxofre $(1,00)$, metomil $(0,60)$ e tiodicarbe $(0,15)$ foram moderadamente persistentes (classe 3) (16-30 dias de ação nociva) e lambda-cialotrina 250 (0,10), espinosade $(0,10)$ e lambda-cialotrina + tiametoxam $(0,25)$, foram persistentes (classe 4$)$ (> 31 dias de ação nociva sobre T. pretiosum).

Palavras-chave: controle biológico; controle químico; parasitoide de ovos; persistência biológica; Zea mays.

\section{ABSTRACT}

\section{Residual action of pesticides sprayed on corn plants on Trichogramma pretiosum}

The objective of this study was to evaluate the residual effect of nine pesticides and a fungicide/acaricide on the parasitoid Trichogramma pretiosum Riley, 1879, in field conditions. Corn plants were sprayed with pesticides up to the runoff point three days before assembling the bioassays. Anagasta kuehniella (Zeller, 1879) eggs were offered in blue cardstock cards, individualized within the cages. The newly emerged adults of T. pretiosum were released in the proportion of 1.6 female per egg of the alternative host. Releases of the parasitoids were performed at 3, 10, 17, 24, and 31 days after spraying the plants. The pesticides were classified by their persistence, following the scale proposed by IOBC. The results showed that the commercial/active ingredients ( $\mathrm{kg}$ or L ha. $\left.{ }^{-1}\right)$, used in corn, beta-cyfluthrin $(0.10)$, cypermethrin (0.08), chlorpyrifos (1.00), lambda-cyhalothrin 50 (0.15), methomyl (0.60), sulfur (1.00), and thiodicarb (0.15) were moderately persistent (class 3; 6-30 days of harmful action) and lambda-cyhalothrin 250 (0.10), lambdacyhalothrin + thiamethoxam (0.25), and spinosad (0.10) were persistent (Class 4; > 31 days of harmful action) on $T$. pretiosum.

Key words: biological control; biological persistence; chemical control; egg parasitoid; Zea mays.

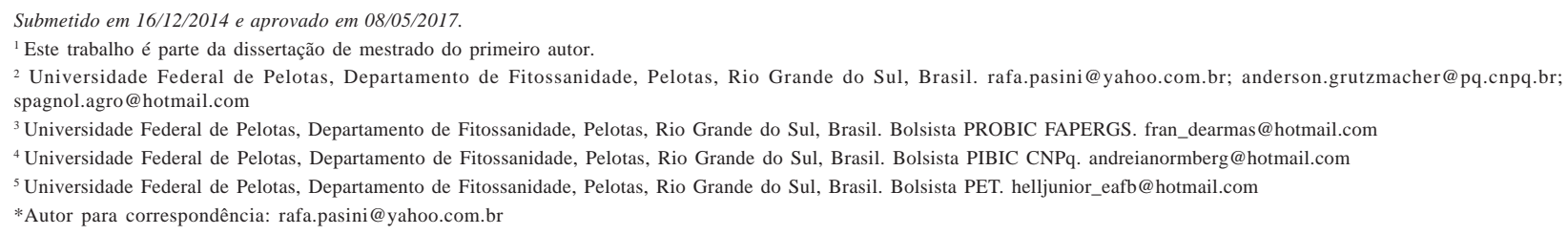




\section{INTRODUÇÃO}

Entre os insetos-praga da cultura do milho, a lagartado-cartucho Spodoptera frugiperda (Smith, 1797) (Lepidoptera: Noctuidae) e a lagarta-da-espiga Helicoverpa zea (Boddie, 1850) (Lepidoptera: Noctuidae) são os principais causadores de prejuízos (Figueiredo et al., 2006; Foresti et al., 2012). Além delas, nos últimos anos, Helicoverpa armigera (Hübner, 1805) (Lepidoptera: Noctuidae), que era praga quarentenária ausente, vem ganhando destaque, principalmente por ser uma espécie altamente polífaga, de difícil controle e que já foi constatada causando prejuízos à cultura do milho (Ávila et al., 2013).

O controle desses insetos-praga ainda é rotineiramente realizado com inseticidas, que muitas vezes são aplicados sem se seguirem os princípios do manejo integrado de pragas (MIP) (Cruz, 2007). O uso de agrotóxicos de maneira abusiva e inadequada, em vez de controlar eficientemente uma determinada praga, pode ocasionar mais problemas para a agricultura, como a contaminação ambiental, o aumento de resíduos nos alimentos e a eliminação dos insetos benéficos, promotores do controle biológico natural. Por essa razão, o uso de métodos alternativos de controle de pragas na cultura do milho apresenta-se como de grande importância, na busca de se minimizar esses efeitos (Oliveira \& Ávila, 2010). Dentre esses métodos, destaca-se o controle biológico por meio do uso de parasitoides e predadores (Maia, 2009).

Parasitoides do gênero Trichogramma (Hymenoptera: Trichogrammatidae) caracterizam-se por serem inimigos naturais de $S$. frugiperda, $H$. zea e $H$. armigera, tendo como principal vantagem o controle desses lepidópterospraga na fase de ovo, impedindo a eclosão da lagarta e o consequente dano à cultura (Sá \& Parra, 1993; Cruz, 1995). No Brasil, T. pretiosum tem sido liberado em lavouras comerciais, como ocorreu, em 2008, em aproximadamente 3.000 hectares de culturas de milho, no município de Santa Maria, RS, para o controle da lagarta-do-cartucho (Nava \& Nachtigal, 2010).

Para que os controles químico e biológico possam ser utilizados, em conjunto, nas lavouras de milho, é de suma importância o estudo e a utilização de agrotóxicos seletivos aos inimigos naturais (Delpuech et al., 2005). Para a cultura do milho, algumas pesquisas sobre a ação residual de agrotóxicos, envolvendo T. pretiosum, foram realizadas, utilizando-se a metodologia proposta pela "International Organization for Biological and Integrated Control of Noxious Animals and Plants (IOBC) West Palaearctic Regional Section (WPRS)" (Stefanello Júnior et al., 2012). Contudo, elas usaram condições ambientais controladas de casa de vegetação e de laboratório, além de espécie vegetal padrão (videira) para classificar os agrotóxicos. Em semicampo, com condições ambientais não controladas e utilizando-se plantas de milho, os agrotóxicos podem se comportar de forma diferente da observada em laboratório e em casa de vegetação, quanto a sua persistência, mostrando, de forma mais realística, sua persistência sobre os adultos de T. pretiosum.

Por essa razão, o objetivo deste trabalho foi avaliar a ação residual de nove inseticidas e de um fungicidaacaricida, em plantas de milho, sobre adultos do parasitoide T. pretiosum, em telado com condições ambientais de semicampo, e utilizando a escala de persistência da IOBC/ WPRS.

\section{MATERIAIS E MÉTODOS}

Os ensaios foram realizados no município de Capão do Leão (1743'19'’ S - 48 09'35' O, aos 13 m de altitude), na Universidade Federal de Pelotas (UFPel), sob telado, em condições de semicampo.

Para avaliar o efeito residual dos agrotóxicos sobre adultos de $T$. pretiosum, as plantas de videira (padrão) foram substituídas por plantas de milho, sendo os produtos classificados de acordo com a escala da IOBC/WPRS para persistência biológica (Hassan et al., 2000; Hassan \& Abdelgader, 2001).

A criação de T. pretiosum foi iniciada com espécimes coletados sobre ovos do hospedeiro $H$. zea na cultura do milho, no município de Pelotas, RS e, posteriormente, mantida em ovos do hospedeiro alternativo Anagasta kuehniella (Zeller, 1879) (Lepidoptera: Pyralidae).

Para os ensaios foi utilizado o híbrido de milho 30F53, da Pioneer $^{\circledR}$. As plantas de milho foram cultivadas em vasos plásticos $\left(0,99 \mathrm{~m}^{3}\right)$, sendo semeadas quatro sementes por vaso. Foi usado fertilizante 05-20-20, como adubação de base e, ureia, como de cobertura, na proporção de 80 $\mathrm{kg}$ por hectare, conforme a análise de solo e as exigências da cultura (Emygdio et al., 2013). Após a germinação, as plantas de milho foram mantidas em telado, em condições ambientais de semicampo. Antes da instalação dos experimentos, as plantas foram desbastadas, permanecendo duas por vaso.

Os agrotóxicos (Tabela 1) foram utilizados, na máxima dosagem registrada para a cultura do milho (Agrofit, 2014), e diluídos, considerando-se um volume de calda proporcional a $200 \mathrm{~L}_{\text {de água ha }}{ }^{-1}$. As plantas de milho foram pulverizadas até o ponto de escorrimento, quando atingiram o estádio vegetativo V5 (cinco folhas completamente desenvolvidas). No tratamento testemunha, a pulverização foi realizada somente com água destilada. Depois de pulverizadas, as plantas permaneceram em temperatura ambiente, para evaporação do excesso de umidade, formando-se, assim, uma película seca do agrotóxico sobre as folhas. 
Posteriormente, as plantas foram transferidas para um telado coberto com lona transparente, para evitar que o resíduo dos agrotóxicos na superfície das folhas fosse lavado pela água da chuva. Para a realização dos ensaios, as plantas foram individualizadas no interior de gaiolas de madeira $(60 \times 60 \times 1,40 \mathrm{~cm})$, revestidas com tecido voile branco.

Passados os períodos de 3, 10, 17, 24 e 31 dias após a pulverização (DAP), foram ofertados às plantas ovos de A. kuehniella, aderidos a cartelas de cartolina azul, perfazendo uma área de $0,25 \mathrm{~cm}^{2}$ ( \pm 125 ovos), os quais foram inviabilizados sob lâmpada germicida por período de uma hora. Cada cartela recebeu uma gotícula de mel para a alimentação dos parasitoides. A cada liberação de $T$. pretiosum, as cartelas, em número de seis por gaiola, foram fixadas nas inserções das folhas, nos terços superior, médio e inferior de cada planta (Carvalho et al., 1999; 2002).

Tubos de vidro com adultos recém-emergidos de $T$. pretiosum foram utilizados para a liberação dos parasitoides no interior das gaiolas, na proporção de aproximadamente 1,6 fêmea por ovo do hospedeiro alternativo (Carvalho et al., 2002). A cada liberação, a gaiola foi aberta e o tubo com parasitoides foi fixado em posição vertical junto à base da planta e, imediatamente após, a gaiola foi fechada durante o período de exposição. As liberações de T. pretiosum foram realizadas aos 3, 10, 17, 24 e 31 DAP das plantas, a fim de se avaliar a ação residual dos agrotóxicos sobre a capacidade de parasitismo dos adultos de T. pretiosum.

As cartelas com os ovos foram expostas ao parasitismo por um período de 24 horas, retiradas e acondicionadas em câmara climatizada, regulada à temperatura de $25 \pm 2$ ${ }^{\circ} \mathrm{C}$, umidade relativa de $70 \pm 10 \%$ e fotofase de 14 horas, para a posterior avaliação dos ovos parasitados (ovos escuros), com microscópio estereoscópico.
Graças à capacidade do telado, foram realizados dois ensaios para a avaliação da persistência dos agrotóxicos sobre T. pretiosum. Cada ensaio foi constituído de cinco agrotóxicos diferentes, mais uma testemunha negativa (água destilada), e avaliado consecutivamente por cinco semanas $(3,10,17,24$ e 31 DAP). O delineamento experimental utilizado foi o de blocos casualizados, testando-se apenas um fator (agrotóxico), com seis tratamentos e quatro repetições, sendo a parcela experimental constituída de uma planta, com seis cartelas com ovos do hospedeiro.

$\mathrm{Na}$ condição em que os ensaios foram realizados, formigas atuaram como predadoras de ovos de A. kuehniella. Por essa razão, foi necessário avaliar a percentagem de ovos que foi predada. A percentagem de predação natural dos ovos em cada ensaio foi calculada por meio da fórmula:

$P(\%)=\frac{I-F}{I} \times 100 \%$, em que:

I - total de ovos da infestação artificial; F - total de ovos recolhidos do semicampo após a liberação; P - predação (Sá \& Parra, 1993; Salamina \& Parra, 1998).

A redução do parasitismo, causada pelos produtos, comparada com a causada pelo tratamento testemunha, foi utilizada como parâmetro de classificação da toxicidade dos agrotóxicos. Utilizou-se a fórmula $\mathrm{RP}=(1-\mathrm{Rt} / \mathrm{Rc}) \mathrm{x}$ 100, em que RP é a percentagem de redução do parasitismo, Rt é o valor do parasitismo médio para cada produto e Rc o parasitismo médio observado para o tratamento testemunha (negativa). Com base nessas percentagens de redução do parasitismo, os agrotóxicos foram classificados, semanalmente, segundo os índices propostos pela IOBC/WPRS, em: classe 1, inócuo (<30\%); classe 2, levemente nocivo (30-79\%); classe 3, moderadamente nocivo (80-99\%), e classe 4, nocivo (> 99\%). Quando os agrotóxicos se mostraram inócuos (Classe 1) em dois en-

Tabela 1: Agrotóxicos utilizados na cultura do milho e avaliados nos ensaios de ação residual para adultos de Trichogramma pretiosum, em condições de semicampo, utilizando-se a dosagem máxima do produto comercial registrada para a cultura

\begin{tabular}{llcccc}
\hline Ingrediente ativo & Grupo químico & Classe $^{(1)}$ & DC $^{(2)}$ & C.i.a. $^{(3)}$ & C.p.c. $^{(4)}$ \\
\hline cipermetrina & Piretroide & I & 0,08 & 0,008 & 0,040 \\
lambda-cialotrina + tiametoxam & Piretroide + Neonicotinoide & I & 0,25 & $0,013+0,017$ & 0,125 \\
lambda-cialotrina 50 & Piretroide & I & 0,15 & 0,003 & 0,075 \\
lambda-cialotrina 250 & Piretroide & I & 0,10 & 0,012 & 0,050 \\
enxofre & Inorgânico & F/A & 1,00 & 0,400 & 0,500 \\
metomil & Metilcarbamato de oxima & I & 0,60 & 0,064 & 0,300 \\
tiodicarbe & Metilcarbamato de oxima & I & 0,15 & 0,060 & 0,075 \\
clorpirifós & Organofosforado & I & 1,00 & 0,240 & 0,500 \\
espinosade & Espinosinas & I & 0,10 & 0,024 & 0,050 \\
beta-ciflutrina & Piretroide & I & 0,10 & 0,002 & 0,050 \\
\hline
\end{tabular}

${ }^{(1)} \mathrm{A}=$ acaricida, $\mathrm{F}$ = fungicida, $\mathrm{I}=$ inseticida;

${ }^{(2)} \mathrm{DC}=$ Dosagem de campo $\left(\mathrm{kg} \mathrm{ou} \mathrm{L} \mathrm{ha}{ }^{-1}\right.$ do produto comercial) considerando um volume de calda de $200 \mathrm{~L}^{-1}$;

${ }^{(3)}$ C.i.a. = Concentração $(\%)$ do ingrediente ativo na calda utilizada nos ensaios;

${ }^{(4)}$ C.p.c. $=$ Concentração $(\%)$ do produto comercial na calda utilizada nos ensaios. 
saios consecutivos foram classificados de acordo com a escala de persistência biológica da IOBC/WPRS, em: classe 1 , vida curta ( $<5$ dias); classe 2 , levemente persistente $(5-$ 15 dias); classe 3, moderadamente persistente (16-30 dias), e classe 4, persistente (> 31 dias).

Para as análises estatísticas, foi utilizado o software Assistat 7.7 (Silva \& Azevedo, 2016). As médias de ovos parasitados foram testadas quanto à normalidade pelo teste de Shapiro-Wilk. Para variáveis que apresentaram distribuição normal, foi realizada análise de variância (ANOVA) e as médias foram comparadas pelo teste de Tukey, a 5\% de probabilidade de erro. As variáveis que não apresentaram distribuição normal foram transformadas em $\sqrt{\mathbf{x}}$, para atenderem à pressuposição de normalidade e, posteriormente, comparadas pelo teste de Tukey, a $5 \%$ de probabilidade de erro.

\section{RESULTADOS E DISCUSSÃO}

De acordo com a análise estatística, verificou-se que, na avaliação aos 17 DAP, os tratamentos com betaciflutrina, clorpirifós e tiodicarbe não apresentaram diferença significativa quanto ao número de ovos parasitados, quando comparados com a testemunha. No entanto, os valores obtidos mostraram redução do parasitismo superior a 30\% (Figura 1) e, por isso, os inseticidas foram classificados como levemente nocivos (classe 2) a $T$. pretiosum, nesse período de avaliação. Observou-se ainda que, para a maioria dos tratamentos dos ensaios 1 e 2 (Tabela 2), o resultado do tratamento testemunha não diferiu estatisticamente do resultado dos tratamentos com os agrotóxicos considerados inócuos (classe 1), betaciflutrina, clorpirifós e tiodicarbe, aos 24 DAP e betaciflutrina, clorpirifós, lambda-cialotrina 50 e tiodicarbe aos 31DAP, e, no ensaio 2, dos resultados com cipermetrina, enxofre e metomil aos 31DAP.

No ensaio 1 (Tabela 2), os inseticidas beta-ciflutrina, clorpirifós e tiodicarbe apresentaram redução do parasitismo inferior a $30 \%$, somente a partir dos 24 DAP, e lambda-cialotrina 50, a partir dos 31 DAP (Figura 1), sendo eles considerados moderadamente persistentes (classe 3) para controle dos adultos do parasitoide (Tabela 2). Lambda-cialotrina+tiametoxam, formulado em mistura com ingredientes ativos (piretroide e neonicotinoide), mostrouse tóxico ao longo das cinco semanas, apresentando, aos 31 DAP, 58,73\% de redução do parasitismo (Figura 1), sendo categorizado como persistente (classe 4) para controle dos adultos de T. pretiosum (Tabela 2).

No ensaio 2 (Tabela 2), cipermetrina, enxofre e metomil apresentaram toxicidade aos adultos de $T$. pretiosum até os 24 DAP, com redução do parasitismo inferior a 30\%, na última avaliação, aos 31 DAP, sendo categorizados como moderadamente persistentes (classe 3). Os inseticidas espinosade e lambda-cialotrina 250 apresentaram redução do parasitismo superior a $30 \%$ até o último período de avaliação (Figura 2) e, por isso foram categorizados como persistentes (classe 4).

Stefanello Júnior et al. (2012) testaram a persistência de lambda-cialotrina+tiametoxam e, como neste estudo, também classificaram o produto como persistente (classe 4), com alta toxicidade, durante as cinco semanas de teste para os adultos de T. pretiosum. Apesar de não terem sido encontrados resultados na literatura para tiametoxam, a elevada toxicidade pode ser devida ao ingrediente ativo lambda-cialotrina, na maior concentração em lambda-cialotrina+tiametoxam $(0,01325 \%$ de i.a. na calda), quando comparado com o efeito de seu uso isolado em lambda-cialotrina $250(0,0125 \%)$, sendo que, aos 31 DAP, o inseticida ainda reduziu o parasitismo em $58,73 \%$ (Figura 1 ).

Stefanello Júnior et al. (2012) classificaram o clorpirifós $(0,24 \%$ de i.a. na calda) como moderadamente persistente (classe 3) para o parasitoide T. pretiosum. Nörnberg et al. (2011) verificaram os seus efeitos nocivos até a terceira semana (17 DAP), classificando o inseticida como moderadamente persistente (classe 3). Esses resultados corroboram os obtidos neste trabalho, em que clorpirifós foi classificado como moderadamente persistente (classe 3), com redução do parasitismo inferior a $30 \%$ a partir dos 24 DAP (Figura 1). Em trabalho desenvolvido por Hassan (1994), no entanto, o ingrediente ativo clorpirifós foi classificado como persistente (classe 4) para Trichogramma cacoeciae Marchal, 1927 (Hymenoptera: Trichogrammatidae), mostrando a importância de se testarem os ingredientes ativos formulados, pois, como visto, a formulação pode interferir na toxicidade do agrotóxico.

O inseticida metomil foi classificado como moderadamente persistente (classe 3), com redução do parasitismo aos 24 DAP de 45,98\% (Figura 2), discordando do resultado observado por Hassan (1983) para T. cacoeciae, que classificou o produto como persistente (classe 4) para controle do parasitoide. Dentre os fatores que podem ter influenciado esse resultado, cita-se a condução do trabalho em telado, sem controle das condições ambientais, e a espécie de parasitoide estudada, uma vez que T. pretiosum pode apresentar susceptibilidade ao agrotóxico diferente da apresentada por T. cacoeciae.

Nörnberg et al., (2011) e Giolo et al., (2005) classificaram o fungicida-acaricida enxofre como persistente (classe 4) para controle dos adultos de T. pretiosum, resultado que também foi obtido por Grützmacher et al. (2004), porém para o parasitoide $T$. cacoeciae. No entanto, neste trabalho, esse produto foi classificado como moderadamente persistente (classe 3), apresentando redução do parasitismo aos 31 DAP de 13,99\% (Figura 2). 
T్ర Tabela 2: Número médio de ovos parasitados ( \pm EP) por Trichogramma pretiosum, classes de toxicidade de agrotóxicos usados na cultura do milho e percentagem de predação, para os ensaios de ação residual em condições de semicampo

Dias após a pulverização das plantas

\begin{tabular}{|c|c|c|c|c|c|c|c|c|c|c|c|c|c|}
\hline \multirow{3}{*}{ Produto } & \multicolumn{11}{|c|}{ Dias após a pulverização das plantas } & \multicolumn{2}{|c|}{ Persistência } \\
\hline & \multirow{2}{*}{$\mathbf{D C}^{(1)}$} & \multicolumn{2}{|c|}{3} & \multicolumn{2}{|c|}{10} & \multicolumn{2}{|c|}{17} & \multicolumn{2}{|l|}{24} & \multicolumn{2}{|l|}{31} & \multirow[b]{2}{*}{ Dias } & \multirow[b]{2}{*}{$\mathbf{C P} \mathbf{P}^{(4)}$} \\
\hline & & $\begin{array}{c}\text { Ovos } \\
\text { parasitados }^{(2)}\end{array}$ & $\mathbf{C}^{(3)}$ & $\begin{array}{c}\text { Ovos } \\
\text { parasitados }\end{array}$ & $\mathbf{C}$ & $\begin{array}{c}\text { Ovos } \\
\text { parasitados }\end{array}$ & $\mathbf{C}$ & $\begin{array}{c}\text { Ovos } \\
\text { parasitados }\end{array}$ & $\mathbf{C}$ & $\begin{array}{c}\text { Ovos } \\
\text { parasitados }\end{array}$ & $\mathbf{C}$ & & \\
\hline \multicolumn{14}{|c|}{ Bioensaio 1} \\
\hline Testemunha & - & $132,37 \pm 6,82 \mathrm{a}$ & - & $63,02 \pm 4,86 a$ & - & $96,38 \pm 6,47 a$ & - & $38,88 \pm 4,27 \mathrm{a}$ & - & $62,75 \pm 3,73 a$ & - & - & $\underline{-}$ \\
\hline lambda-cialotrina + tiametoxam & 0,25 & $6,75 \pm 2,45 d$ & 3 & $0,69 \pm 0,21 \mathrm{~d}$ & 3 & $19,93 \pm 2,83 \mathrm{c}$ & 2 & $6,69 \pm 2,11 \mathrm{c}$ & 3 & $25,90 \pm 5,93 b$ & 2 & $>30$ & 4 \\
\hline lambda-cialotrina 50 & 0,15 & $15,81 \pm 1,46 \mathrm{~cd}$ & 3 & $2,43 \pm 1,02 \mathrm{~cd}$ & 3 & $40,67 \pm 3,42 b c$ & 2 & $9,69 \pm 2,11 b c$ & 2 & $52,12 \pm 1,99 a$ & 1 & $16-30$ & 3 \\
\hline tiodicarbe & 0,15 & $34,44 \pm 5,56 b c$ & 2 & $28,81 \pm 4,27 \mathrm{ab}$ & 2 & $64,75 \pm 6,28 \mathrm{ab}$ & 2 & $30,06 \pm 1,85 \mathrm{ab}$ & 1 & $54,64 \pm 3,39 \mathrm{a}$ & 1 & $16-30$ & 3 \\
\hline clorpirifós & 1,00 & $49,81 \pm 6,79 b$ & 2 & $22,81 \pm 3,60 b$ & 2 & $57,00 \pm 5,27 \mathrm{abc}$ & 2 & $32,81 \pm 4,77 \mathrm{a}$ & 1 & $59,79 \pm 3,57 \mathrm{a}$ & 1 & $16-30$ & 3 \\
\hline beta-ciflutrina & 0,10 & $35,06 \pm 7,95 b c$ & 2 & $8,31 \pm 1,52 \mathrm{bc}$ & 3 & $66,00 \pm 4,45 \mathrm{ab}$ & 2 & $38,88 \pm 3,02 \mathrm{a}$ & 1 & $58,28 \pm 4,81 \mathrm{a}$ & 1 & $5-15$ & 3 \\
\hline$\overline{\text { Predação }^{(5)}(\%)}$ & & 0,68 & & 1,46 & & 1,43 & & 7,15 & & 6,5 & & & \\
\hline \multicolumn{14}{|c|}{ Bioensaio 2} \\
\hline Testemunha & - & $99,95 \pm 8,67 \mathrm{a}$ & - & $56,95 \pm 6,52 \mathrm{a}$ & - & $48,25 \pm 2,11 \mathrm{a}$ & - & $59,06 \pm 6,32 \mathrm{a}$ & - & $63,60 \pm 6,78 \mathrm{a}$ & - & - & 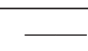 \\
\hline cipermetrina & 0,08 & $16,60 \pm 4,32 b$ & 3 & $21,00 \pm 7,97 \mathrm{c}$ & 2 & $18,25 \pm 2,07 \mathrm{~b}$ & 2 & $39,30 \pm 1,31 b$ & 2 & $48,40 \pm 5,62 \mathrm{a}$ & 1 & $16-30$ & 3 \\
\hline lambda-cialotrina 250 & 0,10 & $16,65 \pm 4,42 b$ & 3 & $8,95 \pm 3,27 \mathrm{c}$ & 3 & $2,15 \pm 0,95 \mathrm{c}$ & 3 & $8,10 \pm 2,62 d$ & 3 & $12,90 \pm 1,91 \mathrm{~b}$ & 2 & $>30$ & 4 \\
\hline enxofre & 1,00 & $19,10 \pm 4,45 b$ & 3 & $20,65 \pm 4,70 b$ & 2 & $8,65 \pm 3,55 b c$ & 3 & $26,69 \pm 2,33 b c$ & 2 & $54,70 \pm 4,87 \mathrm{a}$ & 1 & $16-30$ & 3 \\
\hline metomil & 0,60 & $21,90 \pm 2,77 b$ & 2 & $23,25 \pm 3,88 b$ & 2 & $10,25 \pm 2,28 b$ & 2 & $31,90 \pm 2,70 b$ & 2 & $54,90 \pm 5,28 \mathrm{a}$ & 1 & $16-30$ & 3 \\
\hline espinosade & 0,10 & $18,25 \pm 4,78 b$ & 3 & $13,25 \pm 1,72 b$ & 2 & $12,54 \pm 2,13 b$ & 2 & $16,88 \pm 8,15 \mathrm{~cd}$ & 2 & $23,70 \pm 1,93 b$ & 2 & $>30$ & 4 \\
\hline
\end{tabular}

Predação $^{(5)}(\%)$

3,02

2,78

2,81

3,43

3,78

${ }^{(1)} \mathrm{DC}=$ Dosagem de campo (kg ou L ha-1 do produto comercial) considerando um volume de calda de $200 \mathrm{~L}^{-1} \mathrm{ha}^{-1}{ }^{(2)}$ Médias seguidas pela mesma letra minúscula na coluna, não diferem significativamente entre si pelo teste de Tukey ( $\mathrm{p}>0,05$ ), Ensaio 1 (3DAP: $\mathrm{F}=32,19 ; \mathrm{gl}=5 ; \mathrm{p}=0,0001 ; 10 \mathrm{DAP}: \mathrm{F}=28,85 ; \mathrm{gl}=5 ; \mathrm{p}=0,0001 ; 17 \mathrm{DAP}: \mathrm{F}=8,94 ; \mathrm{gl}=5 ; \mathrm{p}=0,0003 ; 24 \mathrm{DAP}$ : F= 9,19; gl= 5; p= 0,0003; 31DAP: $\mathrm{F}=6,60 ; \mathrm{gl}=5 ; \mathrm{p}=0,0019$ ) Ensaio 2 (3DAP: F= 8,25; gl= 5; $\mathrm{p}=0,0006 ; 10 \mathrm{DAP}: \mathrm{F}=146,69 ; \mathrm{gl}=5 ; \mathrm{p}=0,0001 ; 17 \mathrm{DAP}: \mathrm{F}=31,28 ; \mathrm{gl}=5 ; \mathrm{p}=0,0001 ; 24 \mathrm{DAP}: \mathrm{F}=33,69 ; \mathrm{gl}=5 ; \mathrm{p}=0,0001 ; 31 \mathrm{DAP}: \mathrm{F}=15,03$; $\mathrm{gl}=5 ; \mathrm{p}=0,0001) ;{ }^{(3)} \mathrm{C}=$ Classes da IOBC/WPRS em função da redução de parasitismo: 1 =inócuo $(<30 \%), 2=$ levemente nocivo (30-79\%), 3=moderadamente nocivo $(80-99 \%), 4=$ nocivo $(>99 \%) ;\left({ }^{(4)} \mathrm{CP}\right.$ = Classes da IOBC/WPRS, para testes de persistência biológica: $1=$ vida curta $\left(<5\right.$ dias); $2=$ levemente persistente $\left(5-15\right.$ dias); $3=$ moderadamente persistente $(16-30$ dias $) ; 4=$ persistente $\left(>30\right.$ dias). ${ }^{(5)}$ Média de predação em cada experimento durante as cinco semanas de ensaio. 
Para o inseticida espinosade, resultados semelhantes aos deste trabalho foram obtidos por Stefanello Júnior $e t$ al. (2012), que classificaram o produto comercial utilizado na cultura do milho, como persistente (classe 4) para controle dos adultos de T. pretiosum. Segundo os autores, esse inseticida afetou o parasitoide por cinco semanas consecutivas, com 97,83\% de redução do parasitismo aos 31 DAP. A redução observada neste trabalho foi de $62,73 \%$ (Figura 2).

O efeito tóxico de lambda-cialotrina 250 para $T$. pretiosum foi observado até os $31 \mathrm{DAP}$, com redução do parasitismo de 79,71\% (Figura 2), corroborando os resultados de Stefanello Júnior et al. (2012), que classificaram o produto como persistente (classe 4) para esse parasitoide. Carvalho et al. (1999) também observaram que o ingrediente ativo lambda-cialotrina $\left(0,025 \mathrm{~g}\right.$ i.a. $\left.\mathrm{L}^{-1}\right)$ foi persistente para duas linhagens de T. pretiosum, em casa de vegetação, apresentando redução média de parasitis- mo, aos 31 DAP, de aproximadamente $60 \%$. Esses autores atribuíram a baixa taxa de parasitismo observada a um efeito repelente desse inseticida. Para T. cacoeciae, Hassan (1994) observou resultados similares, em experimentos com lambda-cialotrina ( $0,075 \%$ de concentração do ingrediente ativo na calda), classificando-o como persistente. No caso de lambda-cialotrina 50, com a utilização de uma concentração de ingrediente ativo $70 \%$ menor do que a de lambda-cialotrina 250, aos 24 DAP, ocorreu redução do parasitismo de 75,07\% (Figura 1), sendo classificado como moderadamente persistente (classe 3).

Neste trabalho pôde-se observar que estudos em condições próximas às de campo podem acelerar a degradação do produto e influenciar na classificação final de persistência do agrotóxico, como observado para os inseticida metomil e o fungicida-acaricida enxofre. Ainda é importante ressaltar que as plantas foram cultivadas em telado coberto e após a aplicação dos inseticidas permaneceram

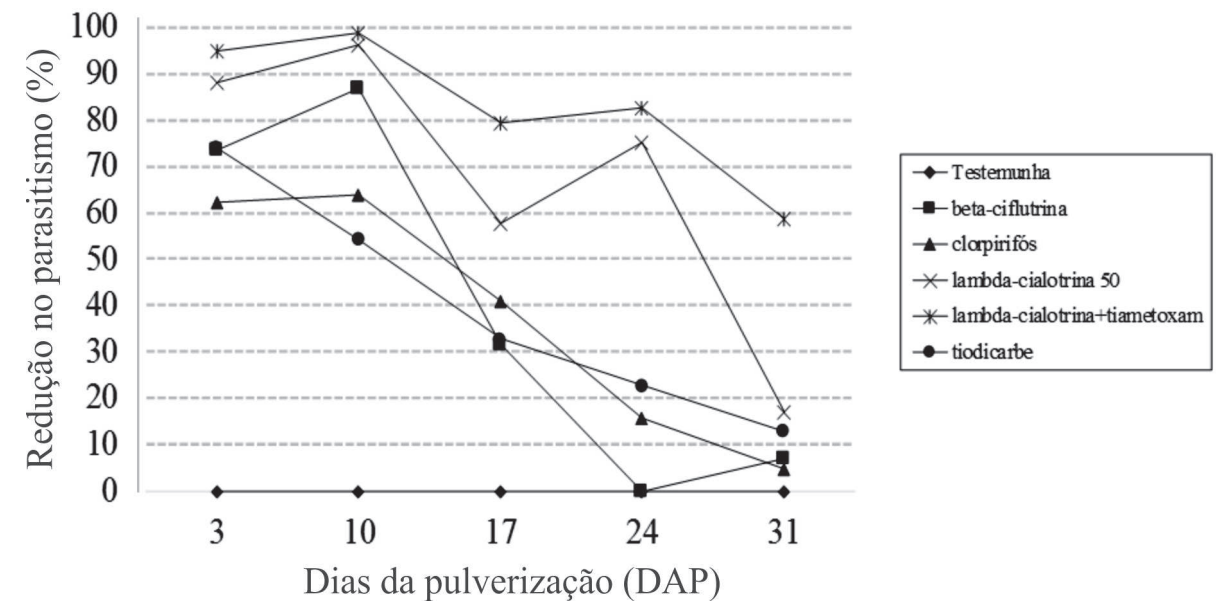

Figura 1: Ação residual de agrotóxicos usados na cultura do milho (Bioensaio 1) na percentagem de redução do parasitismo de Trichogramma pretiosum, em telado (condições ambientais de semicampo).

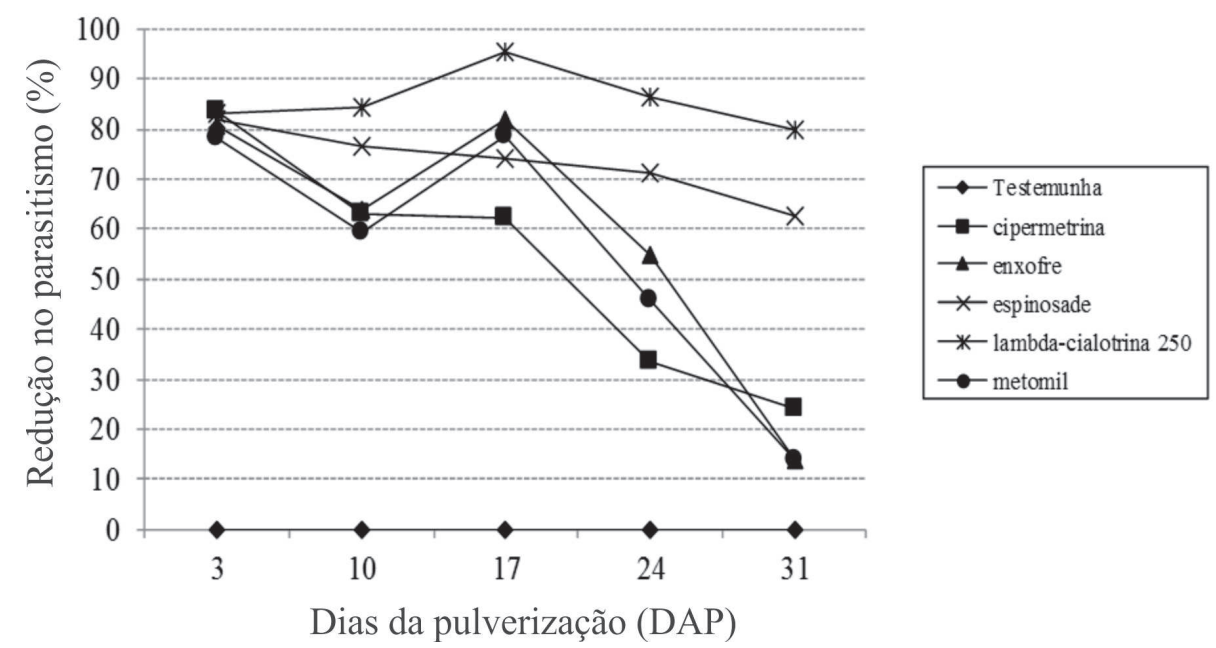

Figura 2: Ação residual de agrotóxicos usados na cultura do milho (Bioensaio 2) na percentagem de redução do parasitismo de Trichogramma pretiosum, em telado (condições ambientais de semicampo). 
31 dias com os resíduos dos agrotóxicos em suas folhas, constituindo esse o pior cenário possível para determinação da toxicidade dos agrotóxicos. No campo, essa situação dificilmente aconteceria, pois as plantas estão sujeitas a diversos fatores climáticos, entre eles a chuva. Nesse sentido, citam-se resultados obtidos por Maia et al. (2016), que testaram a persistência de inseticidas sobre larvas de Chrysoperla carnea (Stephens, 1836) (Neuroptera: Chrysopidae), em plantas de milho, com e sem a presença de chuva, e obtiveram redução do potencial nocivo do inseticida clorpirifós quando as plantas de milho foram submetidas a um regime de chuva de $11 \mathrm{~mm}$, mostrando, assim, que, no campo, a chuva pode resultar em menor persistência dos agrotóxicos.

Em relação à percentagem de predação dos ovos de $A$. kuehniella por formigas, no ensaio 1 houve um maior percentual de predação de ovos a partir dos 24 DAP em comparação com o mesmo parâmetro no ensaio 2 (Tabela 2). Um dos fatos que explicam essa diferença é que, no ensaio 1, os inseticidas beta-ciflutrina, tiodicarbe e clorpirifós apresentaram-se como inócuos (classe 1) a partir dos 24 DAP, evidenciando menor toxicidade também sobre os agentes de predação natural dos ovos (formigas), e com isso, uma maior percentagem de predação. No ensaio 2, aos 31 DAP, em que cipermetrina, enxofre, espinosade e metomil foram inócuos para T. pretiosum, foi observada percentagem de predação maior que nos outros períodos de avaliação (3, 10, 17 e 24 DAP) (Tabela 2).

Não foram encontrados dados de persistência para todos os produtos usados nos ensaios. Contudo, resultados distintos desses, de outro autores, provavelmente se devem às diferentes condições ambientais em que foi realizado este estudo. Sabe-se que a persistência de um agrotóxico na superfície das plantas está diretamente relacionada com processos degradativos bióticos e abióticos, juntamente com a volatilização, que tem uma forte dependência da temperatura, sendo que, em diferentes condições climáticas, são encontrados valores de volatilização diferentes para uma mesma molécula (Silva $\&$ Fay, 2004). Este estudo foi conduzido com plantas cultivadas em telado, sem controle de temperatura e de umidade relativa do ar, nos meses de novembro a janeiro, que se caracterizam por temperaturas máximas elevadas, no RS. Nessas condições, a temperatura sob o telado alcançou valores acima de $35^{\circ} \mathrm{C}$, o que, provavelmente, contribuiu para uma aceleração dos processos de degradação dos agrotóxicos.

Dos dez agrotóxicos testados, três foram persistentes (classe 4) e sete foram moderadamente persistentes (classe 3) para controle de $T$. pretiosum. De acordo com a metodologia da IOBC/WPRS, todos os agrotóxicos, considerados moderadamente persistentes e persistentes, devem passar para a fase de campo em lavoura comercial de milho, a fim de se obter a classificação final da seletividade desses agrotóxicos para o parasitoide, sendo esta a última etapa dos testes propostos pela IOBC/ WPRS. De modo geral, todos os agrotóxicos avaliados apresentaram-se tóxicos para os adultos de T. pretiosum, sendo necessário cautela na adoção desses produtos em programas de MIP. Deve-se, sempre que possível, optar por produtos que apresentem efeito menos danoso aos inimigos naturais e ao meio ambiente como um todo.

\section{CONCLUSÕES}

A respeito dos produtos comerciais-ingredientes ativos ( $\mathrm{Kg}$ ou L ha $\left.{ }^{-1}\right)$, quanto ao efeito sobre os adultos do parasitoide de ovos $T$. pretiosum, pode-se concluir que beta-ciflutrina $(0,10)$ lambda-cialotrina $(0,15)$, tiodicarbe $(0,15)$, clorpirifós $(1,00)$, cipermetrina $(0,08)$, enxofre $(1,00)$ e metomil $(0,60)$ são moderadamente persistentes (classe 3) (16 a 30 dias de ação nociva) e lambda-cialotrina + tiametoxam $(0,25)$, lambda-cialotrina $(0,10)$ e espinosade $(0,10)$ são persistentes (classe 4$)$ (> 31 dias de ação nociva).

\section{AGRADECIMENTOS}

Os autores agradecem ao Conselho Nacional de Desenvolvimento Científico e Tecnológico $(\mathrm{CNPq})$ e à Coordenação de Aperfeiçoamento de Pessoal de Nível Superior (CAPES), pelo apoio financeiro para a realização desta pesquisa.

\section{REFERÊNCIAS BIBLIOGRÁFICAS}

Agrofit (2014) Sistema de agrotóxicos fitossanitários. Disponível em: <http://extranet.agricultura.gov.br/agrofit_cons/principal_agrofit_cons>. Acessado em: 28 de novembro de 2014.

Ávila CJ, Vivan LM \& Tomquelski GV (2013) Ocorrência, aspectos biológicos, danos e estratégias de manejo de Helicoverpa armigera (Hübner) (Lepidoptera: Noctuidae) nos sistemas de produção agrícolas. Dourados, Embrapa Agropecuária Oeste. 12p. (Circular Técnica, 23).

Carvalho GA, Parra JRP \& Baptista GC (1999) Ação residual de alguns inseticidas pulverizados em plantas de tomateiro sobre duas linhagens de Trichogramma pretiosum Riley, 1879 (Hymenoptera: Trichogrammatidae) em casa de vegetação. Ciência e Agrotecnologia, 23:770-775.

Carvalho GA, Reis PR, Moraes JC, Fuini LC, Rocha LCD \& Goussain MM (2002) Efeitos de alguns inseticidas utilizados na cultura do tomateiro (Lycopersicon esculentum Mill.) a Trichogramma pretiosum Riley, 1879 (Hymenoptera: Trichogrammatidae). Ciência e Agrotecnologia, 26:1160-1166.

Cruz I (1995) A lagarta-do-cartucho na cultura do milho. Sete Lagoas, Embrapa/Centro Nacional de Pesquisa de Milho e Sorgo. 45p. (Circular Técnica, 21).

Cruz I (2007) Alternativas para o controle da lagarta-do-cartucho, Spodoptera frugiperda e principais cuidados no uso de milhos transgênicos resistentes a insetos. In: Fancelli AL \& Dourado Neto D (Eds.) Milho: fatores determinantes da produtividade. Piracicaba, USP-ESALQ. p.79-105. 
Delpuech JM, Bardon C \& Boulétreau M (2005) Increase of the behavioral response to kairomones by the parasitoid wasp Leptopilina heterotoma surviving insecticides. Archives of Environmental Contamination and Toxicology, 49:186-191.

Emygdio BM, Afonso-Rosa APS \& Teixeira MCC (2013) Indicações técnicas para o cultivo de milho e de sorgo no Rio Grande do Sul - Safras 2013/2014 e 2014/2015. $58^{a}$ Reunião técnica anual do milho $/ 41^{\mathrm{a}}$ Reunião técnica anual do sorgo, Pelotas. Embrapa Clima Temperado. 124p.

Figueiredo MLC, Martins-Dias AMP \& Cruz I (2006) Relação entre a lagarta-do-cartucho e seus agentes de controle biológico natural na produção de milho. Pesquisa Agropecuária Brasileira, 41:1693-1698.

Foresti J, Garcia MS, Bernardi O, Zart M \& Nunes AM (2012) Biologia, seleção e avaliação de linhagens de Trichogramma spp. para o controle da lagarta-da-espiga em milho semente. EntomoBrasilis, 5:43-48.

Giolo FP, Grützmacher AD, Manzoni CG, Fachinello JC, Nörnberg SD \& Stefanello Júnior GJ (2005) Seletividade de agrotóxicos indicados na produção integrada de pêssego a Trichogramma pretiosum Riley, 1879 (Hymenoptera: Trichogrammatidae). Revista Brasileira de Fruticultura, 27:222-225.

Grützmacher AD, Zimmermann O, Yousef A \& Hassan SA (2004) The side-effects of pesticides used in integrated production of peaches in Brazil on the egg parasitoid Trichogramma cacoeciae Marchal (Hym., Trichogrammatidae). Journal of Applied Entomology, 128:377-383.

Hassan SA (1983) Procedure for testing side effects of pesticides on beneficial arthropods as being considered by the International Working Group "Pesticides and Beneficial Arthropods". Mitteilungen der Deutschen Gesellschaft für Allgemeine und Angewandte Entomologie, 4:86-88

Hassan SA (1994) Comparison of three different laboratory methods and one semi-field test method to assess the side effects of pesticides on Trichogramma cacoeciae. IOBC/WPRS Bulletin, 17:133-141.

Hassan SA \& Abdelgader H (2001) A sequencial testing program to assess the effects of pesticides on Trichogramma cacoeciae Marchal (Hym., Trichogrammatidae). IOBC/WPRS Bulletin, 24:71-81.

Hassan SA, Halsall N, Gray AP, Kuehner C, Moll M, Bakker FM, Roembke J, Yousef A, Nasr F \& Abdelgader HA (2000) A laboratory method to evaluate the side effects of plant protection products on Trichogramma cacoeciae Marchal (Hym., Trichogrammatidae). In: Candolfi MP, Blümel S, Forster R, Bakker FM, Grimm C, Hassan SA, Heimbach U, Mead-Briggs MA, Reber B, Schmuck R \& Vogt H (Eds.) Guidelines to evaluate side-effects of plant protection products to non-target arthropods. Reinheim, IOBC/WPRS. p.107-119.
Maia JB (2009) Seletividade de inseticidas, utilizados na cultura do milho (Zea mays L.), para Trichogramma atopovirilia Oatman \& Platner, 1983 (Hymenoptera: Trichogrammatidae). Dissertação de Mestrado. Universidade Federal de Lavras, Lavras. $47 \mathrm{p}$.

Maia JB, Carvalho GA, Medina P, Garzón A, Gontijo PC \& Viñuela E (2016) Lethal and sublethal effects of pesticides on Chrysoperla carnea larvae (Neuroptera: Chrysopidae) and the influence of rainfastness in their degradation pattern over time. Ecotoxicology, 25: 845-855.

Nava DE \& Nachtigal GF (2010) Controle biológico no Sul do Brasil. Revista de Controle Biológico, 1:15-18.

Nörnberg SD, Grützmacher AD, Kovaleski A, Finatto JA \& Paschoal MDF (2011) Persistência de agrotóxicos utilizados na produção integrada de maçã a Trichogramma pretiosum. Ciência e Agrotecnologia, 35:305-313.

Oliveira HN \& Ávila CJ (2010) Controle biológico de pragas no Centro-Oeste brasileiro. Revista de Controle Biológico, 11-13. (Edição Especial).

Sá LAN \& Parra JRP (1993) Capacidade de dispersão de Trichogramma pretiosum Riley, 1879 para controle de Helicoverpa zea (Boddie, 1850) em milho. Scientia Agricola, 50:226-231.

Salamina BAZ \& Parra JRP (1998) Capacidade de dispersão de Trichogramma pretiosum Riley, 1879 para o controle de Anticarsia gemmatalis Hübner, 1818 em soja. Scientia Agricola, 55:133-137.

Silva FAS \& Azevedo CAV (2016) The assistat software version 7.7 and its use in the analysis of experimental data. African Journal of Agricultural Research, 11:3733-3740.

Silva CMS \& Fay EF (2004) Agrotóxicos e ambiente. Brasília, Embrapa Informação Tecnológica. 400p.

Stefanello Júnior GJ, Grützmacher AD, Spagnol D, Pasini RA, Bonez C \& Moreira DC (2012) Persistência de agrotóxicos utilizados na cultura do milho ao parasitoide Trichogramma pretiosum Riley, 1879 (Hymenoptera: Trichogrammatidae). Ciência Rural, 42:17-23. 